\title{
Strategic Financial Management Global Technology - Case Study
}

\section{Mourad Mazouni*}

Society of Actuaries, 475 North Martingale, Suite 800, Schaumburg, IL 60173, USA

\begin{abstract}
This report aims to critically appraise the significance of strategic management and decision making to the performance of a selected multinational organization and apply and critique the various forms of internal and external business and strategic analysis and formulation.

We also evaluate the relevant financial theories relevant to financial decision making. We further critically apply strategic implementation techniques such as balanced scorecard and portfolio management tools within Cirrus logic and examined how these financial decision making concepts help the electronic manufacturer giant in making effective decisions.

Finally, we examined Cirius's organizational culture and stakeholder management and carried out a stakeholder analysis and discussed the findings and their implication in the multinational decision-making fabric.
\end{abstract}

\section{Introduction}

Cirrus logic, a company which manufactures integrated circuits and has design centres and offices in various other locations such as U.K. Sweden, Spain, Australia, China, South Korea, Japan, Singapore Taiwan and a manufacturing facility in Scotland, U.K. has been chosen for the analytical study.

\section{Strategic management and decision making}

i. Strategy: The Company's strategy is to focus on growing markets where it can leverage on its expertise in Analog and Digital signalling process to solve complex problems [1].

Suggestion: Strategy should be more specific. It is suggested that strategy should clearly state that the company plans to achieve a minimum growth rate of $32 \%$ and $17 \%$ (This is based on an increase in sales and net income of F.Y. 2017 figures).

ii. Business objectives: Since the products of the company are mostly proprietary for which second source of supply is not available, customer service is of prime importance. Customer services to domestic customers are provided through sales offices located in California and Texas. Customer service to foreign buyers is provided from sales offices located in Japan, China, Singapore, South Korea and Taiwan.

The company recognises that its future success depends on its ability to attract, retain and motivate its employees.

Suggestion: Company should introduce a structured program for updating knowledge and enhancing the skills of all employees on an on-going basis.

iii. Growth: Sales and net profits of the company for last 3 years are mentioned in Table 1.

Company has registered healthy growth rate of sales between 32 to $28 \%$ in last 3 financial years. Its net income percentage also increased from $6 \%$ in 2015 to $17 \%$ in 2017. In spite of decrease in Non Portable and other products segment, there has been a significant growth in audio and other products segment, primarily due to increase in sales of smart codecs and boosted amplifiers.

Suggestion: Only revenue of 2 segments is reported, but tracking of results of the segments is not done. Segment wise income and expenditure accounts should be maintained to enable the management to know whether Non Portable Audio and other segment are adding any value to the business.

iv. Financing: At the end of F.Y. 2018, the debt obligations of the company were $\$ 373,685$. Out of this debts payable within 1 year amounted to $\$ 227,512$ including wafer purchase commitments amounting to $\$ 182,331$.

Suggestions: The Company may approach the bank for further loans to pay the wafer purchase commitments and to reschedule the short term loans to bank. The bank may consider the proposal of the company favourably since the company has achieved respectable growth in sales and profitability over the last 3 years.

v. Core values: Company does not have a mission statement incorporating the core values of the Company [2].

Suggestion: Suggested mission statement as mentioned below may be incorporated;

We aim to achieve excellence in products and services.

We promote creative thinking.

We believe in team work.

We believe in fulfilling our duties to society and country.

We conform to the highest ethical standards.

We recognise and reward the contribution of all associates.

Relevant academic theories applicable to internal and external factors of an organisation

i. Internal analysis: Mckinsey 7- S model consists of 7 independent factors.

*Corresponding author: Mourad Mazouni, Society of Actuaries, 475 North Martingale, Suite 800, Schaumburg, IL 60173, USA, Tel: 512-2006949; E-mail: me37@hw.ac.uk

Received July 26, 2018; Accepted August 20, 2018; Published August 22, 2018

Citation: Mazouni M (2018) Strategic Financial Management Global Technology Case Study. Int J Econ Manag Sci 7: 538. doi: 10.4172/2162-6359.1000538

Copyright: (c) 2018 Mazouni M. This is an open-access article distributed under the terms of the Creative Commons Attribution License, which permits unrestricted use, distribution, and reproduction in any medium, provided the original author and source are credited. 


\begin{tabular}{|c|c|c|c|}
\hline & $\mathbf{2 0 1 7}$ & $\mathbf{2 0 1 6}$ & $\mathbf{2 0 1 5}$ \\
\hline Net Sales & $\$ 1.5$ billion & $\$ 1.2$ billion & $\$ 916.6$ million \\
\hline Growth\% & $32 \%$ & $28 \%$ & $\mathbf{2 8} \%$ \\
\hline Net income\% & $17 \%$ & $11 \%$ & \\
\hline Segment Sales & & & \\
\hline Portable Audio Products & $\$ 13,73,848$ & $\$ 9,89,101$ & $\$ 7,40,301$ \\
\hline Non Portable Audio and others & $\$ 1,65,092$ & $\$ 1,80,150$ & $\$ 1,76,267$ \\
\hline
\end{tabular}

Table 1: Sales and net profits of the company for last 3 years.

(a) Strategy: Action Plan to maintain and build competitive advantage over competitors.

(b) Structure: Who reports to whom?

(c) Systems: The procedures to be followed for doing the routine jobs.

(d) Shared Values: It is the core value of a company as represented by the corporate culture and work ethics.

(e) Style: Leadership Style.

(f) Staff: Employee capabilities.

(g) Skills: Employee skills.

The performance of an organisation depends on how well the aforesaid seven elements have been aligned [3].

ii. Value chain analysis: This analysis helps the company in identifying parts which will create value and parts that will not create too much value. After identification companies should concentrate on those aspects which would help in reducing costs.

iii. External analysis: Mentioned very briefly are the external factors which have to be analysed.

Pest analysis: PEST means Political, Economic, Social and Technological factors [4]. PESTEL analysis means PEST plus legal and environmental factors.

PESTLIED Analysis: Means PESTLEL plus international and demographic factors

iv. Porter's five forces

It is a simple tool developed for understanding the external business environment;

(a) Competitive Rivalry: Number of competitors and their strength.

(b) Supplier Power: Power of suppliers to increase their prices.

(c) Buyer Power: Power of customers to reduce prices.

(d) Threat of Substitution: Development of products at cheaper prices.

(e) Threat of new entries: How easy it is to enter company's line of business [5].

\section{Strategic financial theories}

There are many financial theories. But based on their relevance to the task in hand, the most important theories are,
(a) Agency theory
(b) Modern Portfolio theory

(c) Dividend signalling theory.

i. Agency theory: In large companies the principal (shareholders) and agents (persons in charge of management) are different persons. This may result in conflict of interests. Agents are normally expected to work for achieving the objectives laid down by the principals but often it is found that agent is more interested in achieving his personal goals which may be in conflict with that of the principal. Agency theory attempts to reconcile this difference. This can be done by free flow of information so that agents are fully aware of the objectives of their principals and the principals are aware of the decisions and actions taken by agents on their behalf [6].

ii. Modern portfolio theory: This is an investment theory which seeks to maximise the portfolio's returns by diversification. The investors normally seek to minimise the risks and if the risks are higher, the investors will also expect higher returns.

\section{(c) Dividend signalling theory}

Empirical studies have conclusively established that when a company declares dividend at a higher rate, then the share prices also increase. Investors assume that since the managers have complete information about the operations and finances of a company, declaration of higher is a signal to the market that future prospects of the company are very bright. Investors will acquire shares either for the purposes of selling them at a higher rate in future or holding the shares in expectation of receiving handsome dividends. Reverse happens when a company does not declare dividends or declares dividend at a lower rate [7].

\section{Theory applications to financial decision making}

So far, we have identified and defined the prevailing Strategic Finance theories. In this section, we will examine how these concepts can be applied to effective financial decision-making frameworks:

i. Agency Theory: The following procedures of Cirrus Logic, ensures that the risks of conflicting interests is reduced substantially.

- Different persons are appointed as Chairman of Board of Directors and as Chief Executive Officer thereby ensuring that more detailed information is available to the Board.

- Excepting CEO, all other members of the Board are independent directors.

- Although management is responsible for managing all risks, the Board plays an active role in overseeing the risk management process. It reviews all significant strategic and operational risks and steps taken by the management to mitigate it.

- The compensation committee consisting solely of independent directors, also reviews the compensation programme and structuring of awards to ensure that it does not lead to undue risk taking by managers. 
- Governance and Nomination committee oversees the risks relating to corporate governance policies and related governance matters.

- Audit committee also comprising solely of independent directors, reviews with the management all major regulatory and financial risks procedure (including cybersecurity related risks) and steps taken by the management to control such exposure.

- The Audit Committee is also responsible for appointment and fixation of remuneration of independent auditor.

- A code of conduct has been framed which applies to all directors, officers and employees.

ii. Modern Portfolio theory: This does not apply to this case study.

iii. Dividend Signalling theory: Stock prices of the company have been highly volatile. However, the Annual Report does not mention non- payment of dividends in cash, as one of the reasons for the volatility. (Cirrus Annual report, 2017, p 21) The company has not paid any dividends in cash and will continue with the policy of retaining earnings. (Cirrus Annual report, 2017, p 22) The movement of prices of common stock in 2016 and 2017 are shown in the Table 2 enclosed below.

The quarterly volatility in share prices is due to the variations in quarterly earnings as mentioned in the Annual report. Further in-spite of not paying cash dividends, there has been a significant increase in share prices. It seems that the market has rewarded the company for achieving good growth in sales and net income.

Therefore the dividend signalling theory is not proved in this case.

\section{Strategic implementation technique using balance score card and portfolio management technique}

i. BCG matrix: The BCG matrix is a framework introduced by the Boston Consulting Group to assess the strategic position of a business brand portfolio and its potential. It categorizes a business portfolio into four classes based on industry attractiveness (growth rate of that industry) and competitive position (relative market share) comprises of the following elements.

Star: A star is a business unit or products that have a large market share and also generates the most cash. Because of their high growth rates they also consume the most cash. So the cash generated is also mostly by them. If properly nurtured Stars can become Cash Cows. Companies should continue to invest in Stars.

Cash Cows: Generates surplus cash for the company. They are market leaders but do not have prospects for future growth. A company in order to maintain productivity may continue to invest in them or it may continue to enjoy the benefits of surplus cash generated without making further investments in such units.

Dogs: Units or Products that have a low market share and also a low growth rate. They mostly operate at break- even levels. So they do not

\begin{tabular}{|c|c|c|c|c|}
\hline Period & 2016 (High) & 2016 (Low) & $\mathbf{2 0 1 7}$ (High) & $\mathbf{2 0 1 7}$ (Low) \\
\hline $1^{\text {st }}$ Quarter & 38.2 & 31.95 & 40.98 & 31 \\
\hline $2^{\text {nd }}$ Quarter & 36.03 & 28.11 & 58.08 & 34.82 \\
\hline $3^{\text {rd }}$ Quarter & 37.6 & 24.56 & 59.78 & 49.05 \\
\hline $4^{\text {th }}$ Quarter & 36.95 & 25.09 & 64.16 & 52 \\
\hline
\end{tabular}

Table 2: Movement of prices of common stock in 2016 and 2017. generally generate surplus cash for the company and if their do not start generating cash flows in the near future, the company may consider divestment of such units.

Question mark: Units or Products that have high growth prospects but presently having a low market share. They also consume a lot of cash. Companies should continue investing in them. However if it is found subsequently that expectation of high growth prospects was misplaced, then the company should sell them off.

\section{Conclusion}

Based on the above analysis Portable Audio Segment may be classified as a Star business of Cirrus Logic, which has the potential of becoming a cash cow.

Non Portable Audio and other business segment falls either under the category of dogs or falls under Question Mark category. Generation of data and further analysis is required [8].

\section{The role of culture in corporate strategy}

For understanding organisation culture, a person will also have to know the basic principles of its incorporation, heritage and the market and customers served by it. In today's world of Global Mergers, Amalgamations, Acquisitions understanding the culture of the organisation has become critical for the success of all restructuring exercises. The failure of the Daimler Chrysler merger process has been attributed to the cultural clash. Organisations which have successfully completed the merger/ amalgamation/ acquisition process have followed 3 basic principles.

i. Understanding the differences in global cultures: For instance if a Japanese company takes over an American company then it is very important for the Japanese company to understand, the mindset of its employees, suppliers, customers and other business associates in America.

ii. Understanding what culture means to different people even within the same country and within the same organisation.

For instance Finance department may feel that the marketing department is selling goods on credit to persons whose ability and willingness to pay is suspect, whereas the marketing department feels that for establishing the product in the market risks have to be taken and some bad debts are inevitable.

iii. Balance of strategy and culture: It is important to bring about cultural changes in the acquired companies gradually. Any radical changes sought to be made within a very short time span is bound to be resisted. So the ideal solution would be to align company's strategy to its culture. Though some cultural changes would be inevitable after the takeover by new management, still this approach has a better chance of succeeding then bringing about sudden disruptive changes [9].

Organisation culture means shared beliefs, norms and values, which usually forms the basis of strategy. Successful implementation of strategy is possible only if it is fully integrated with organisation culture. A stable culture creates an environment for unity, team work and cooperation [10].

For establishing culture, organisational goals have to be first identified. A company should not start its operations without first identifying its goals. Moreover the goals should be long term. The long term goals can be split up into Annual, Quarterly and monthly goals. When a leader communicates the goals to his team, there is clarity about 
what is expected from the team. Thus the goal set, acts as a benchmark for measuring actual performance. The long term goals may be revised based on the actual performance [11].

\section{Stakeholder's analysis}

Three steps are involved in stakeholder's analysis.

i. The first step is to identify who are the stakeholders.

A complete list of all persons who could be affected by the project should be included in this list. For instance they could be Shareholders, Business Associates, Suppliers, Lenders, Senior Executives, Colleagues, Customers, Government, Trade Associations, Press, Community, Advisors/ Consultants, Various interest groups etc.

ii. The next step is to identify who are the important stakeholders whose cooperation will be required.

Now all identified stakeholders have to be divided into 4 categories.

- Those who have the power to block the project or facilitate in its completion and who are interested in the project.

- $\quad$ Stakeholders who have the power but are not interested.

- Then there are stakeholders who are interested in the project but do not have the power.

- The stakeholders falling under the last category are those who do not have the power and are also not interested in the project.

iii. The last step would be come to an understanding with the important stakeholders so that the project can be completed smoothly.

Based on the aforesaid categorisation different strategies should be adopted for handling the stakeholders.

Highest priority should be accorded to persons who fall under the first category and all out efforts should be made in coming to an understanding with them.

Efforts should be made to satisfy the second category.

The third category of stakeholders should always be kept informed.

The last category should only be monitored [12-15].

This method may also be applied for bringing cultural change in an organisation.

\section{Stakeholders analysis applications in an organisation}

Stakeholders Analysis is done before introducing any major changes in an organisation. Therefore it is also applicable when a foreign multinational acquires a company in another country or establishes a green field project abroad.
Panasonic Corporation had acquired a number of companies overseas, spread across various countries. It did not do a proper stakeholder's analysis at the time of acquisition. It also did not make use of its overseas human resources since all decision making authority was concentrated in Japan $[16,17]$.

However subsequently after this analysis was done, it realised that for achieving further growth it should create autonomous management systems and structure overseas. Global Human Resource initiatives have been taken such as creating a work place environment where opportunities will be provided to every employee to excel and recruiting right person for a job irrespective of their nationality.

President of the corporation has also stated that for achieving growth in the near future it necessary to shift to from a Japan centric management approach to a locally driven model with self-contained organisational capability to complete each task at the respective location. This model has already been implemented in India [1].

It seems that these changes were forced by Stakeholder's having the power to do so such as customers, employees, government and the press.

\section{References}

1. Panasonic Corporation Annual Report (2017).

2. Root G (2018) 10 most important business objectives, n.d.

3. The Mckinsey 7-S Framework (2018) Mindtools, n.d.

4. Pestle Analysis Contributor (2013) Pestle Analysis, n.d.

5. Mind Tools Content Team (2018) Porter's Five Forces.

6. Ingram D (2018) The agency theory in financial management n.d.

7. Simiyu A (2014) Signalling theory of dividends. Journal of Behavioral Finance 1: $1-10$.

8. Martin M (2017) Business News Daily.

9. Roll M (2014) Culture Can Make or Break Strategy, Knowledge.

10. Rose $A(2018)$ The impact of organisational culture on strategy implementation

11. Quain S (2018) Why is goal setting important in organisations.

12. Thompson R (2018) Stakeholder Analysis. Mindtools, n.d.

13. Amir J, Sidhu A (1988) Agency theory: Implications for Financial Management Managerial Finance 14: 1-5.

14. Lucco J (2017) Clear Point Strategy.

15. Superordinate Goals: The Best Conflict Resolution Techniques (2018) PsycholoGenie, n.d.

16. Company Mission Statement Examples (2014).

17. Modern Portfolio theory (2013). 